\title{
Unusual coexistence of Ménétrier disease with adenocarcinoma of the esophagogastric junction: A case report and review of the literature
}

\author{
Olga Prokopchuk $^{1 *}$, Santiago Moreno-Ordaz ${ }^{2}$, Norbert Hüser ${ }^{1}$, Jeannine Bachmann ${ }^{1}$, Björn Konukiewitz ${ }^{3}$, Andrea Delgado-Picolomini², \\ Helmut Friess ${ }^{1}$ and Marc E. Martignoni ${ }^{1}$ \\ ${ }^{1}$ Department of Surgery, Klinikum Rechts der Isar, Technische Universität München, Germany \\ ${ }^{2}$ Department of Surgery, The American British Cowdray Medical Center, Mexico \\ ${ }^{3}$ Institute of Pathology, Technische Universität München, Germany
}

\begin{abstract}
Menetrier's disease is a rare condition characterized by the presence of gastric hypertrophy due to massive gastric folds, with foveolar infiltration replacing the normal glandular architecture. We present the case of a 46-year-old male patient who was diagnosed with adenocarcinoma of the esophagogastric junction Siewert type II, $\mathrm{uT} 3 \mathrm{uN} 0$. The patient received neoadjuvant chemotherapy. A thoraco-abdominal distal esophagectomy and proximal gastrectomy with stomach tube reconstruction plus local radical lymphadenectomy was performed. Postoperative histopathology revealed Ménetriér's Disease and a smaller-than-thought adenocarcinoma of the esophagogastric junction.
\end{abstract}

\section{Background}

Several esophageal/gastric lesions including diffuse heterotopic gastric glands and granular cell tumors [1], esophageal [2] and gastric [3] tuberculosis, metastases of other primary cancers like breast [4] and lung cancer [5] were reported to mimic advanced esophageal/gastric cancer or adenocarcinoma of the esophagogastric junction (AEG).

Ménétrier's disease (MD) or giant hypertrophic gastritis was first described by french pathologist Pierre Eugene Ménétrier in 1888 while performing a series of autopsies [6]. It is a very rare disease, with only a few hundred published case reports worldwide [7]. MD is characterized by enlargement of gastric mucosal folds associated with foveolar hyperplasia, proliferation of gastric glands and mucoussecreting cells replacing normal chief and parietal cells in extensive cases [8]. The etiology of this disease is still not completely understood $[7,8]$. It has been found that overexpression of transforming growth factor $\alpha(\mathrm{TGF} \alpha)$ and enhanced epidermal growth factor receptor (EGFR) signaling are implicated in the pathophysiology of this disease, however, the true cause of this abnormal activity in local gastric mucosal cells remains unknown $[7,9]$.

In a study with whole exome sequencing in individuals from a family with autosomal dominant Ménétrier disease, it was proposed that NOTCH pathway might be involved in the pathogenesis of Ménétrier syndrome [10].

There are variants of MD where cytomegalovirus (CMV), herpes simplex and Helicobacter pylori infections have been associated as possible causes $[9,11]$. This condition is often found in adults between the ages 40 to 60 years, more commonly in men [7]. Its classical presentation consists of a set of insidious and progressive-appearing symptoms including: epigastric abdominal pain, asthenia, anorexia, vomiting, weight loss, peripheral edema due to hypoalbuminemia and anemia $[8,12]$. On endoscopy enlarged gastric folds with erosion and thick mucous bridges across these folds are found [12]. There are no standardized criteria for its diagnosis [12]. Thick mucosa biopsies should be made in order to look for the typical histopathologic signs that define MD [9]. Clinical and endoscopic findings should be considered for supporting the diagnosis. Other diseases such as hypertrophic lymphocytic gastritis, hypertrophic hypersecretory gastritis, ZollingerEllison syndrome and polyposis syndromes should be ruled out [9]. MD is thought to be a risk factor for developing gastric cancer, although a measurable statistical association has not been established $[7,13]$. A wide variety of treatment modalities have been tried. Supportive measures including pain management and high-protein diet may be useful in many patients [7]. Octreotide and lanreotide use has been reported as a successful way of treatment $[14,15]$. The monoclonal antibody cetuximab has shown to be effective in small series $[16,17]$. Total gastrectomy is reserved for some cases where medical therapy is not effective $[18,19]$.

\section{Case presentation}

We present the case of a 46-year-old male patient with a diagnosis of a Siewert type II esopahogastric adenocarcinoma (AEG II). This diagnosis was made occasionally during a conventional check-up at another institution. The patient had always remained asymptomatic. The patient's past medical history included an episode of meningitis 24 years earlier, an appendectomy, hemorrhoidectomy and a left inguinal hernia repair.

${ }^{\star}$ Correspondence to: Olga Prokopchuk, M.D, Department of Surgery, Klinikum Rechts der Isar, Technical University of Munich. Ismaningerstrasse 22, 81675 Munich, Germany, Tel: 49-8941402145, Fax: 49-89-4140-7207, E-mail olga.prokopchuk@tum.de

Received: May 15, 2018; Accepted: June 12, 2018; Published: June 15, 2018 
An upper gastrointestinal endoscopy revealed an esophageal tumor located at $36 \mathrm{~cm}$ from tongue level (Figure 1A), additionally polypoid formations in the cardiac region (Figure 1B). The primary staging investigations classified the tumor as an uT3, uN0 (Figure 2). CT showed a big tumor volume in the cardiac region of the stomach (Figure 3). After discussion of the case at the Tumor Board of our Hospital, the patient received one cycle of FLOT (5-FU, leucovorin, oxaliplatin and docetaxel) as neoadjuvant chemotherapy. Because of coronary spasms, the FLOT protocol was changed to 3 cycles of Teysuno (tegafur, gimeracil, oteracil). The CEA tumor marker level before the beginning of treatment was measured at $1.88 \mathrm{ng} / \mathrm{ml}$ (normal value). The restaging evaluation including endoscopy, endosonography and $\mathrm{CT}$ after chemotherapy showed no significant response. We performed a thoraco-abdominal distal esophagectomy and proximal gastrectomy with stomach tube reconstruction in the dorsal mediastinum plus local radical lymphadenectomy and simultaneous cholecystectomy.

The postoperative UICC stage of the tumor was a ypT1a $(m), y p N 0$ (0/26 lymph nodes), G1-2 (intestinal type according to Lauren). There was no regression found at the primary tumor after chemotherapy, opposing to regression grade 3 according to Becker. A pattern of hyperthophic gastropathy and massive foveolar polyposis (Figure 4A) with areas of mucosal dysplasia (Figure 4B) was found in the cardiac and paracardiac areas of the stomach, corresponding to MD.
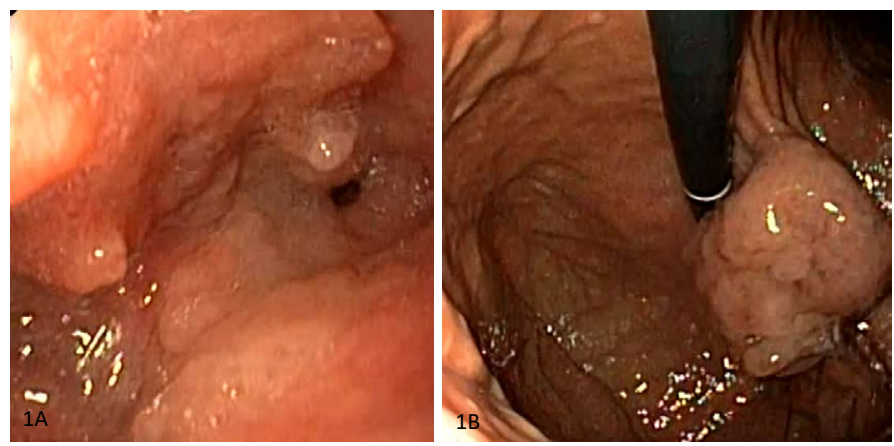

Figure 1. Primary staging studies. Esophagogastroduodenoscopy revealed an AEG Siewert type II junctional tumor $36-40 \mathrm{~cm}$ from tongue level (A), additionally esophagitis grade 2 and macroscopically polypoid formations in inversion (B) without signs of stenosis.

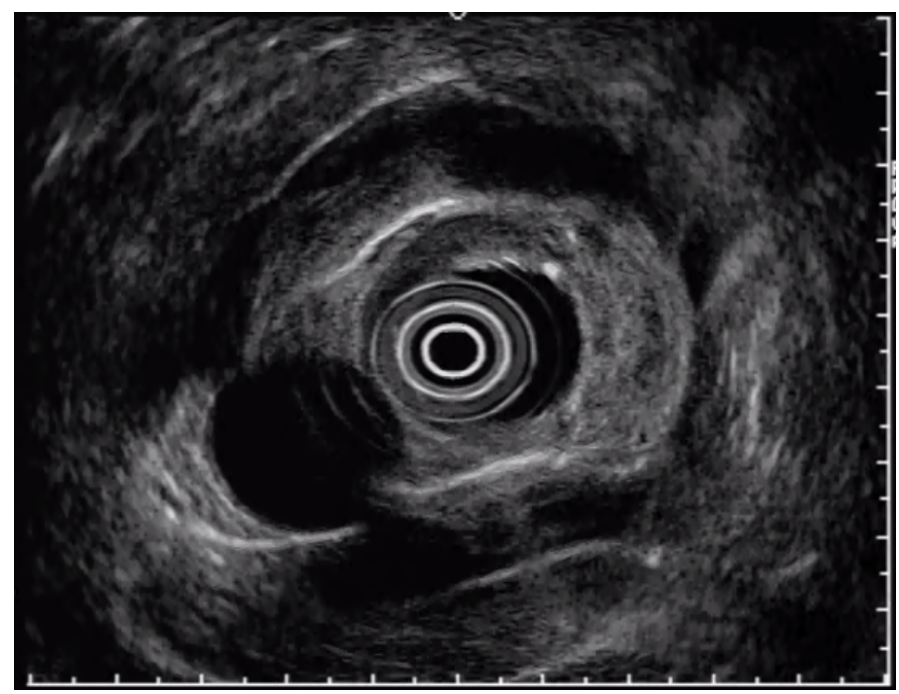

Figure 2. Primary staging studies. Endosonography was difficult in the cardiac part of the stomach because of foveolar hyperplasia, and demonstrated uT3 uN0 tumor.

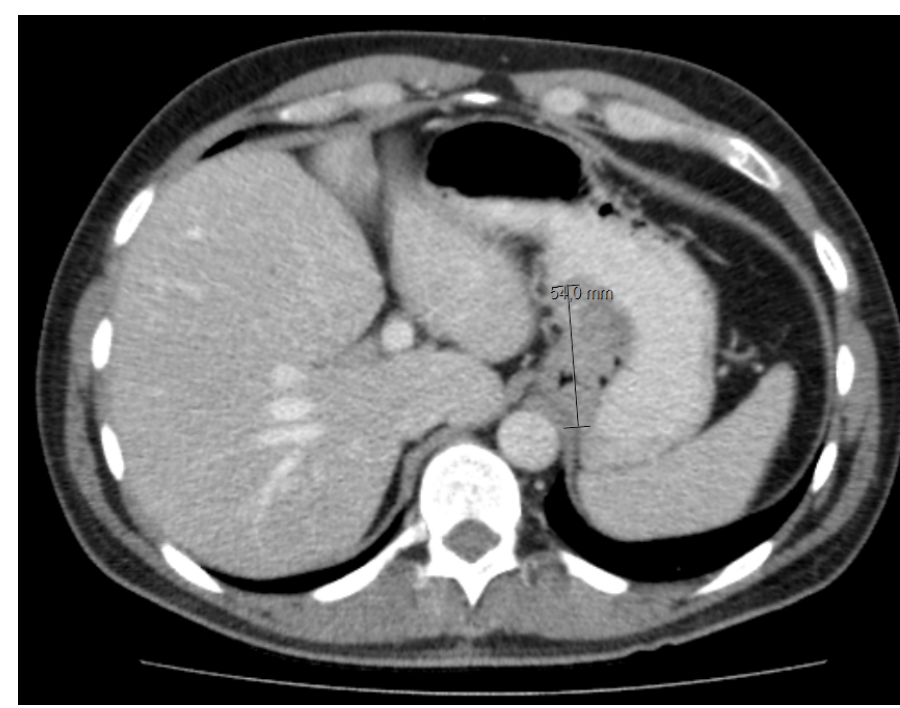

Figure 3. Primary staging studies. Computed tomography showed large tumor mass in the cardiac region of the stomach.

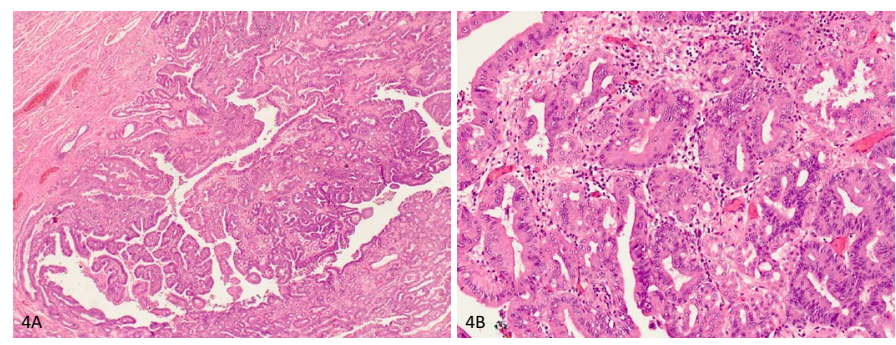

Figure 4. (A) Histologic overview about the specimen shows massive foveolar polyposis with (B) areas of high grade dysplasia in higher magnification

The patient developed a pleural exudate postoperatively, and no surgical complications. Due to a good recovery, he was discharged on postoperative day 15 .

\section{Methods}

Representative areas from the esophagectomy and proximal gastrectomy specimen were sampled in 30 parafin-embedded blocks for light microscopic analysis and immunohistological analysis. CKpanMNF116 monoclonal antibodies were used for the immunohistochemistry study.

\section{Histopathologic findings}

The specimen of the distal esophagectomy had the following dimensions: distal esophagus $7 \mathrm{~cm}$, small curvature of stomach $8 \mathrm{~cm}$, great curvature of stomach $5 \mathrm{~cm}$. The main tumor was found around the cardiac area (Siewert AEG II type), with an exophytic and polypous appearance, stenosing the lumen of the esophagus. Small areas of Barrett's esophagus were found in distal esophagus. Microscopically, the paracardial region of the esophagus, the cardia and the proximal stomach showed typical changes like Ménétrier's disease (Fig. 4A and 4B) with hypertrophic gastropathy and massive foveolar polyposis with low to high grade dysplasia and multifocal an mucosa-invasive intestinal type adenocarcinoma. AEG was found multifocal in areas of high grade dysplasia. The surgical margins in the stomach were free of MD. One lymph node showed regressive changes without detection of residual tumor cells. 


\section{Discussion and conclusion}

The association or coexistence of MD with AEG has not been yet published in the literature. Within this case report, we describe not only unusual association, but also a peculiar type of MD. The topic is of special interest because the number of AEG is increasing [20], even if $\mathrm{MD}$ is a rare gastropathy.

One incongruity with MD description in the literature is the absence of digestive symptoms, typical for MD - vomiting, nausea, diarrhea, abdominal pain, weight loss, malnutrition, postprandial emesis and peripheral edema due to hypoalbuminemia [21]. It is because of this alike set of symptoms that MD is almost never suspected at first in most cases. However, the patient in our case report was never symptomatic.

AEG is usually connected to a mucosal metaplasia and chronic irritation of esophagus by chlorine acid. The very low secretion of chlorine acid is typical for MD [6]. Since, small areas of Barrett's esophagus were found in distal esophagus, this mechanism is also valid in this case.

The patient in this study did not have a coexistent infection with $\mathrm{CMV}$, as many other case reports have described, mainly in pediatric populations [22,23]. Neither did he have an $H$. pylori infection. This is consistent with two other cases we found throughout our research [24,25].

The next incongruity with the literature is based on the extent of $\mathrm{MD}$. We resected maximum of $5 \mathrm{~cm}$ gastric wall in the great curvature. In this patient, MD was limited to the paracardial region of the esophagus, the cardia and the proximal stomach. In most of described cases, MD spares antrum but covers entire stomach till pylorus.

Along with FDA statement, surgical treatment consists in total gastrectomy only as no possible boundary of involved / non-involved gastric wall could be gain. In this case, MD was diagnosed after careful analysis of the esophagectomy and proximal gastrectomy specimen but not pre-operatively. The surgical margins in the stomach were free of MD. This annual endoscopic follow-up demonstrated no signs of MD.

Retrospectively, we can assume that MD mimicked an advanced AEG in this case, and the neoadjuvant chemotherapy probably was not necessary. In the postoperative histology, no regression was found at the primary tumor. Our patient demonstrated agood tumor biology and still alive three years after the operation.

There are numerous case reports in the literature that describe an association between MD and gastric carcinomas [26-28], and even one of them demonstrates association with a hilar cholangiocarcinoma [29]. But to our knowledge, this is the only case report about an AEG and MD.

\section{References}

1. Watanabe Y, Watanabe M, Suehara N, Ishikawa N, Shinkawa T, et al. (2018) Early gastric cancer with diffuse heterotopic gastric glands and granular cell tumors mimicking advanced gastric cancer. Int J Surg Case Rep 46: 41-46. [Crossref]

2. Sharma V, Rana SS, Chhabra P, Sharma R, Gupta N, et al. (2016) Primary esophageal tuberculosis mimicking esophageal cancer with vascular involvement. Endosc Ultrasound 5: 61-62. [Crossref]

3. Kim SE, Shim KN, Yoon SJ, Jung SA, Kim TH, et al. (2006) A case of gastric tuberculosis mimicking advanced gastric cancer. Korean J Intern Med 21: 62-67, 2006. [Crossref]

4. Yim K, Ro SM, Lee J (2017) Breast cancer metastasizing to the stomach mimicking primary gastric cancer: A case report. World J Gastroenterol 23: 2251-2257. [Crossref]

5. Kim MJ, Hong JH, Park ES, Byun JH (2015) Gastric metastasis from primary lung adenocarcinoma mimicking primary gastric cancer. World J Gastrointest Oncol 7: 1216, 2015. [Crossref]

6. Coffey RJ, Tanksley J (2012) Pierre Menetrier and his disease. Trans Am Clin Climatol Assoc 123: 126-133. [Crossref]
7. Lambrecht NW (2011) Ménétrier's disease of the stomach: a clinical challenge. Curr Gastroenterol Rep 13: 513-517. [Crossref]

8. Famularo G, Sajeva MR, Gasbarrone L (2011) Beyond gastritis and before cancer: the strange case of Ménétrier's disease. Intern Emerg Med 6: 369-371. [Crossref]

9. Huh WJ, Coffey RJ, Washington MK (2016) Ménétrier's Disease: Its Mimickers and Pathogenesis. J Pathol Transl Med 50: 10-16. [Crossref]

10. Piccolo P, Attanasio S, Secco I, Sangermano R, Strisciuglio C, et al. (2017) MIB2 variants altering $\mathrm{NOTCH}$ signalling result in left ventricle hypertrabeculation/noncompaction and are associated with Menetrier-like gastropathy. Hum Mol Genet 26: 33-43. [Crossref]

11. Xiong LS, Gong YY (2016) Natural history of adult-onset Ménétrier's disease: Report of a case with 9-year follow-up. Exp Ther Med 11: 2462-2466. [Crossref]

12. Rich A, Toro TZ, Tanksley J, Fiske WH, Lind CD, et al. (2010) Distinguishing Ménétrier's disease from its mimics. Gut 59: 1617-1624. [Crossref]

13. Coffey R, Washington M, Corless C, Heinrich M (2007) Me'ne'trier disease and gastrointestinal stromal tumors: hyperproliferative disorders of the stomach. $J$ Clin Invest 117: 70-80. [Crossref]

14. Green BT, Branch MS (2004) Menetrier's disease treated with octreotide long-acting release. Gastrointest Endosc 60: 1028-1029. [Crossref]

15. Heurgue-Berlot A, Feron T, Jazeron JF, Hoeffel C, Diebold MD, et al. (2016) Menetrier's disease: Long-term remission with lanreotide. Clin Res Hepatol Gastroenterol 40: e5-9. [Crossref]

16. Fiske WH, Tanksley J, Nam KT, Goldenring JR, Slebos RJ, et al. (2009) Efficacy of cetuximab in the treatment of Menetrier's disease. Sci Transl Med 1: 8ra18. [Crossref]

17. Settle SH, Washington K, Lind C, Itzkowitz S, Fiske WH, et al. (2005) Chronic treatment of Ménétrier's disease with Erbitux: clinical efficacy and insight into pathophysiology. Clin Gastroenterol Hepatol 3: 654-659. [Crossref]

18. Sanchez C, Brody F, Pucci E, Bashir S (2007) Laparoscopic total gastrectomy for Ménétrier's disease. J Laparoendosc Adv Surg Tech A 17: 32-35. [Crossref]

19. García-Alvarez MN, Plata-Muñoz JJ, Medina-Franco H (2007) Total gastrectomy in the management of Ménétrier's disease. Institutional experience and review of the literature. Rev Gastroenterol Mex 72: 244-248. [Crossref]

20. Hasegawa S and Yoshikawa T (2010) Adenocarcinoma of the esophagogastric junction: incidence, characteristics, and treatment strategies. Gastric Cancer 13: 63-73, 2010. [Crossref]

21. Rodríguez Gonzalez O, José R, Génesis J, Luis M, Liumariel V, et al. (2015) Robotassisted laparoscopic gastrectomy for Menetrier's disease. J Robot Surg 9: 257-261. [Crossref]

22. Hong J, Lee S, Shon Y (2017) Ménétrier's Disease as a Gastrointestinal Manifestation of Active Cytomegalovirus Infection in a 22-Month-Old Boy: A Case Report with a Review of the Literature of Korean Pediatric Cases. Clin Endosc 51: 89-94. [Crossref]

23. Megged O, Schlesinger Y (2008) Cytomegalovirus-associated protein-losing gastropathy in childhood. Eur J Pediatr 167: 1217-1220. [Crossref]

24. Endo T, Arimura Y, Adachi Y, Mita H, Yamashita K, et al. (2012) A case of Ménétrier's disease without Helicobacter pylori infection. Dig Endosc 24: 275-279. [Crossref]

25. Sweeney A, Lynch M (2013) A case of Ménétrier's disease localized to the gastric antrum without helicobacter infection or hypoalbuminemia. Int J Surg Case Rep 4: 839-841. [Crossref]

26. Pereyra L, Gómez EJ, Mella JM, Casas G, Bugari G, et al. (2011) [Diffuse gastric cancer associated with Ménétrier's disease]. Acta Gastroenterol Latinoam 41: 142-145. [Crossref]

27. Kim TI (2009) [Menetrier's disease accompanied with adenocarcinoma]. Korean $J$ Gastroenterol 53: 271-274. [Crossref]

28. Mellado-Castillero J, Ibáñez-Delgado F, Alcántara-Gijón F, Vázquez-Medina A Hernández de la Torre J (2008) Localized Ménétrier's disease associated with gastric adenocarcinoma. Rev Esp Enferm Dig 100: 60-61.

29. Sato N, Nakahara K, Morita R, et al. (2016) A case of Menetrier's disease seemingly caused by hilar cholangiocarcinoma. The Japanese Journal of Gastro-Enterology 113: 975-982.

Copyright: (C2018 Prokopchuk O. This is an open-access article distributed under the terms of the Creative Commons Attribution License, which permits unrestricted use, distribution, and reproduction in any medium, provided the original author and source are credited. 